\title{
Public responses to water reuse - understanding the evidence
}

\author{
H.M. Smith ${ }^{1 *}$, S. Brouwer ${ }^{2}$, P. Jeffrey ${ }^{1}$, J. Frijns ${ }^{2}$ \\ ${ }^{1}$ Cranfield Water Science Institute, Cranfield University, Bedfordshire, UK, MK43 0AL \\ ${ }^{2}$ KWR Watercycle Research Institute, Post Box 1072, 3430 BB Nieuwegein, \\ *h.m.smith@cranfield.ac.uk
}

\begin{abstract}
Over the years, much research has attempted to unpack what drives public responses to water reuse, using a variety of approaches. A large amount of this work was captured by an initial review that covered research undertaken up to the early 2000s (Hartley 2006). This paper showcases post-millennium evidence and thinking around public responses to water reuse, and highlights the novel insights and shifts in emphasis that have occurred in the field. Our analysis is structured around four broad, and highly interrelated, strands of thinking: 1) work focused on identifying the range of factors that influence public reactions to the concept of water reuse, and broadly looking for associations between different factors; 2) more specific approaches rooted in the socio-psychological modelling techniques; 3) work with a particular focus on understanding the influences of trust, risk perceptions and affective (emotional) reactions; and 4) work utilising social constructivist perspectives and socio-technical systems theory to frame responses to water reuse. Some of the most significant advancements in thinking in this field stem from the increasingly sophisticated understanding of the 'yuck factor' and the role of such pre-cognitive affective reactions. These are deeply entrenched within individuals, but are also linked with wider societal processes and social representations. Work in this area suggests that responses to reuse are situated within an overall process of technological 'legitimation'. These emerging insights should help stimulate some novel thinking around approaches to public engagement for water reuse.
\end{abstract}

\section{Introduction}

In response to emerging water scarcity challenges, many regions of the world are exploring the use of alternative water sources. Water reuse, for both potable and non-potable applications, is one such alternative. It is increasingly seen as an important potential solution to address growing pressures on global water resources (Van der Bruggen 2010) and as part of a more integrated approach to managing the whole water cycle and supporting the circular economy (Michell 2016, Wang 2016). However, negative public opinion has long been recognised as a key challenge to the uptake of reuse schemes (particularly those that 
contribute to the potable water supply). Early research on the subject claimed that, while the technical aspects of water reuse could largely be resolved, it was ultimately "the issue of public acceptance [that] could kill the proposal" (Dishman et al. 1989: 158). Decades later, researchers continue to make similar claims. Some have suggested that 'the people side' of water reuse presents an equal or greater challenge than the technical side (Hartley 2006). More recently, others have argued that public understanding is a 'key factor' in the success (or failure) of reuse schemes (Lazarova et al. 2013), or even that public opposition is currently the 'primary barrier' to the successful implementation of water reuse projects (Ormerod \& Scott 2013).

Such assertions are often rooted in the assumption that a growing number of projects have failed or been abandoned because of negative public responses (Khan \& Gerrard 2006). Water reuse schemes are often seen as less palatable compared to other alternative water supplies (e.g. rainwater harvesting, Fielding et al. 2015) and there are indeed some documented cases of reuse schemes being scaled back or shelved as a direct result of public opposition (as reported in Marks 2006, Brouwer et al. 2015). One particularly well known case, discussed at length in the literature, is that of Toowoomba, Australia (Thorley 2007, Hurlimann \& Dolnicar 2010, Price et al. 2012, Meehan et al. 2013). Here, a proposed indirect potable reuse scheme led to a highly polemic debate and an eventual referendum, in which over $60 \%$ of those who voted opposed the proposal. As a result, the scheme was abandoned.

However, while the Toowoomba case is very well known, it is also relatively unusual - there are few documented cases where public opposition has had such a clear and meaningful impact on the development of a reuse scheme. Indeed, cases of 'successful' reuse schemes that have experienced little or no public opposition are at least as common in literature (e.g. Lazarova et al. 2013). It must be acknowledged that many well established reuse schemes were implemented before public engagement became commonplace as an imperative of water sector planning and management, and have therefore benefited to some degree from a legacy of 'flying under the radar'. However, multiple studies have documented high levels of support for reuse schemes in various contexts (Marks et al. 2006, Friedler 2008, Hills et al. 2013, Brouwer et al. 2015, Smith et al. 2015).

One significant gap in the literature is a relative lack of longer-term longitudinal studies that document whether/how support for reuse schemes can shift over time. However, some examples of widespread shifts in support have been noted. For instance, when the city of San Diego initially proposed an indirect potable reuse scheme in the 1990s, they encountered significant public opposition, and as a result the project was scaled back to a non-potable reuse scheme (Po et al. 2003, Bridgeman 2004, Hartley 2006, Jansen et al. 2007). However, interest in potable reuse was revived in the mid 2000s, and after sustained investment in research and public engagement activities, the city has seen public support for potable reuse rise from 26\% to 73\% between 2004 and 2012 (City of San Diego 2013). In 2014, a twenty-year program was approved to augment the main 
drinking water reservoir with recycled water. The goal is for this scheme to eventually provide about one third of the city's water (City of San Diego 2015).

Despite such recent success stories, within the reuse sector there is still considerable concern over public reactions (Michell 2016), underscoring an ongoing need to develop research in the field. Overall, interest in public responses to water reuse has developed into a highly active and productive area of research, with a substantial associated body of literature encompassing several branches of inquiry. The field has been well served by a small number of review papers, in particular a highly influential contribution from Hartley (2006). However, since publication of this review much has changed. New scholarship has emerged which applies novel disciplinary methods and perspectives to the challenges of understanding community responses to reuse schemes. Water reuse has also expanded and matured as a sector, becoming a more common (and thereby recognisable) feature of water resources planning. Our appreciation of those perceptions, conceptions, beliefs, and opinions which shape public responses to reuse schemes is now conditional on a growing assemblage of psychological, social, and anthropological insights and interpretations. It is time to revisit the literature to answer some important questions about the status, quality, and usefulness of the knowledge base and how its organisation and dominant trends stand up to scrutiny in the context of recent learning. In particular, this contribution poses the following question: Since the early 2000s, what insights have been gained from different social science approaches to understanding public responses towards reuse?

We structure our response to this query around four broad and interrelated strands of thinking which emerge from the post-millennium literature. The first strand, encompassing Hartley's work, involves identifying the range of factors that influence public reactions to the concept of water reuse, and broadly looking for associations between different factors. The second strand is closely related to the first, but takes a more specific approach rooted in the socio-psychological approach of Azjen's theory of planned behaviour. The third strand develops a particular focus on understanding the influences of trust, risk perceptions and affective (emotional) reactions. Finally, the fourth strand utilises social constructivist perspectives and socio-technical systems theory to frame responses to water reuse. These strands are not intended to be mutually exclusive, as much of the work discussed falls across multiple strands, but they allow us to highlight the range of approaches and modes of thinking that have been brought to bear on this field.

Utilising the four strands outlined above, the overall aim of this paper is to illustrate some subtle shifts in emphasis within this body of literature over time, and to present a general picture of the current state of knowledge and emerging trends in the field. In some parts of the paper we also draw insights from a parallel field - that of public reactions to genetically modified (GM) foods. There is a vast body of literature around public reactions to controversial technologies (e.g. nuclear power, nanotechnology) most of which is well beyond the scope of this paper. However, as with recycled water, our potential interactions with GM foods are highly personal (i.e. bodily contact and consumption). Therefore, while 
not an exact or exclusive parallel, studies around public reactions to GM foods offer some of the most translatable insights that can be used to enhance and challenge thinking around public reactions to water reuse.

\section{Identifying the factors that influence public reactions}

Over the years, many studies have attempted to unpack what drives public reactions to reuse schemes, using a variety of approaches. In general, such studies focus on identifying a wide range of factors that influence public reactions, and they broadly examine, to some degree, the associations between those factors.

For example, several researchers have focussed on exploring correlations between demographic characteristics and the attitudes of respondents to reuse schemes. Much of this has been pursued in a theoretical vacuum often with conflicting results as the outcome. Some studies have found women and younger age groups (Po et al. 2005, Porter et al. 2005, Dolnicar et al. 2011, Fielding et al. 2015) or particular religious / ethnic groups (Dolnicar et al. 2011, Hills et al. 2013, Aitken et al. 2014, Garcia-Cuerva 2016) to be more negative and riskaverse towards using water from reuse schemes, whereas higher-income individuals (Hills et al. 2002) and/or people with higher education levels (Garcia-Cuerva 2016) can be more accepting. However, several other studies have found no clear associations between any demographic characteristics and respondents' reactions (Friedler \& Lahav 2006, Smith et al. 2015).

Hartley's (2006) study used a literature review, encompassing evidence produced up to early 2000 , to identify ten underlying factors contributing to the degree of public acceptance of water reuse. The findings suggest that acceptance is higher when: 1) degree of human contact is minimal; 2) protection of public health is clear; 3 ) protection of the environment is a clear benefit of the reuse; 4) promotion of water conservation is a clear benefit of the reuse; 5) cost of treatment and distribution technologies and systems is reasonable; 6) perception of wastewater as the source of reclaimed water is minimal; 7) awareness of water supply problems in the community is high; 8) the role of reclaimed water in overall water supply scheme is clear; 9) perception of the quality of reclaimed water is high; and 10) confidence in local management of public utilities and technologies is high.

The first factor - 'degree of human contact' with recycled water - refers to a body of work that examined the degree to which respondents expressed support for different types of hypothetical reuse schemes. In particular, such studies (including many that have been undertaken since Hartley's review was published) have frequently reported that support tends to drop when the degree of contact respondents are likely to have with recycled water increases. For agricultural irrigation the level of support can vary from one crop to another, depending on (for instance) whether the crop is meant to be eaten uncooked, and the degree to which it might be processed (including washing, peeling, etc.) before consumption (Po et al. 2003, Friedler \& Lahav 2006). Support tends to 
drop off for the idea of using recycled water within homes, and drop even further for the idea of using it for applications involving personal skin contact or the possibility of ingestion, such as bathing and drinking (Bruvold 1985, Hills et al. 2002, Robinson et al. 2005, Marks 2006, Marks et al. 2006, Syme \& Nancarrow 2006, Callaghan et al. 2012). However, these findings must be tempered against the fact that potable reuse schemes, when considered on their own terms (rather than compared against other hypothetical uses), can still generate high levels of support (City of San Diego 2013, Hills et. al 2013, Aitken et al. 2014, Mankad \& Walton 2015).

Hartley's (2006) list of ten factors also stated that public acceptance of reuse is more likely when protection of the environment is a clear benefit; when promotion of water conservation is a clear benefit; and when awareness of water supply problems in the community is high. These three factors are closely interrelated, and their inclusion in Hartley's analysis is partly due to the fact that the regions of the world where water reuse is more commonplace tend to be those that regularly experience water scarcity - notably the U.S. states of California, Texas, and Arizona; Australia; and Mediterranean countries, including Israel and Jordan - or those where there is dependence on what is perceived to be a particularly vulnerable source, such as Singapore (USEPA 2012, Lazarova et al. 2013). These water resource vulnerabilities are often believed to make people more open to the idea of alternative water sources such as reuse (Hurlimann \& Dolnicar 2016). For instance, Dolnicar et al. (2011) concluded that awareness of real water scarcity problems, as well as previous experience with water restrictions, would increase respondents' likelihood of accepting recycled water.

However, real cases have shown that this kind of awareness, on its own, is not necessarily sufficient to improve public support for reuse. For instance, as illustrated in the Toowoomba example, public opposition to reuse has arisen in the midst of a well publicised drought (Hurlimann \& Dolnicar 2010). Additionally, the emphasis on presenting water reuse schemes as a solution to water supply problems, in order to improve their acceptability, presents its own paradox - if the problem disappears, so too might the support for the scheme. Again, this is illustrated in an Australian case (the Western Corridor project) where a large-scale potable reuse scheme was effectively mothballed after completion. This occurred because authorities has stipulated that it would only be used if reservoirs fell below 40\% capacity, which became a highly unlikely scenario after increases in rainfall (Johnstone 2009, Meehan et al. 2013).

One aspect that has been explored more recently is awareness of existing de facto (or unplanned) reuse. Recent findings have illustrated that, while awareness of the real occurrence of de facto reuse is generally low, people who are aware that de facto reuse occurs in their supply area are considerably more likely (up to 10 times more) to have a high level of acceptance for potable reuse scenarios (Rice et al. 2016). This suggests that, rather than awareness of the 'need' for reuse as a solution to water supply issues, awareness of reuse as an existing 'normal' part of the water resource context may be a significant driver of acceptance. 


\section{Socio-psychological modelling approaches}

Echoes of Hartley's work are evident in the application of socio-psychological modelling techniques to quantitatively assess the influence of different factors on respondents' stated intentions of using recycled water, generally for drinking purposes (Po et al. 2003, Po et al. 2005, Syme \& Nancarrow 2006, Nancarrow et al. 2008, Hurlimann et al. 2008, Nancarrow et al. 2009, Dolnicar et al. 2011, Ross et al. 2014). Such studies are generally rooted in Azjen's theory of planned behaviour (Azjen 1985). Their approach involves the a priori identification, often via literature review, of a suite of factors that might shape behavioural decisions around whether to accept or reject recycled water. These factors are then tested and refined through quantitative survey methods, in order to develop structural equation models for assessing and predicting behaviours in response to reuse schemes.

The range of studies included in this strand have added considerable depth to our understanding of the complex interplay between the different factors that shape reactions to water reuse. They have also underscored the overall complexity of these responses and the variations between contexts - each of the models proposed contains a slightly different suite of factors and set of interrelationships. Findings around the roles of certain variables have been mixed. For instance, in one application of this approach (Nancarrow et al. 2009) the initial suite of driving factors incorporated 'knowledge' of water issues and the use of recycled water, but through quantitative testing this factor consistently failed to emerge as a significant predictor of intended behaviour, so it was dropped from the final model. However, another study (Hurlimann et al. 2008) suggested that knowledge could help support trust in the water authority, which could ultimately improve acceptance. Similarly, 'environmental concern' or 'environmental obligation' is often postulated as a factor, but is often found not to be a significant driver of intended behaviour (Hurlimann et al. 2008, Nancarrow et al. 2009). Other variables have emerged as significant drivers, such as the relationship between trust in the organisations managing a given reuse scheme and perceptions of risk - namely that those with more trust in the organisations tend to perceive less risk associated with recycled water (Hurlimann et al. 2008, Ross et al. 2014). The interplay between trust, risk perceptions and emotional reactions ('yuck' factor) has become a key focal point for analysis which will be discussed further in the next strand.

One of the challenges associated with this strand of literature, as well as the strand discussed in the previous section, is its reliance on presenting respondents with hypothetical water reuse scenarios (with the exception of Ross et al. 2014) and its focus on measuring intended behaviour (Hurlimann et al. 2009, Mankad \& Tapsuwan 2011). This is of course consistent with Azjen's overarching theory, which is based on the premise that stated behavioural intentions are good predictors of, and proxies for, actual behaviours. However, the correlation between intended behaviour and actual behaviour cannot be taken for granted, and this is a well known paradox in this style of research. Studies of public reactions to genetically modified (GM) foods, for instance, have illustrated that stated negative opinions towards GM products are not reflected 
in actual purchasing decisions (Sleenhoff \& Osseweijer 2013). One study concluded "[in] situations involving introduction of other novel and controversial technology, SP [stated preference] findings may provide an unrealistically negative view of how consumers will actually respond in a realmarket situation" (Mather et al. 2012: 518). The reason for this discrepancy is thought to be that, for 'socially charged' topics, the choices made by questionnaire respondents are more likely to be influenced by perceptions of societal expectations. In real world situations, on the other hand, more practical considerations such as price-quality evaluations may take precedence in influencing purchasing decisions (Mather et. al 2012). Given that water reuse schemes are often 'socially charged' topics, these findings may well apply, particularly where recycled water is used for drinking purposes. It is important to recognise that asking respondents whether they intend to 'accept' or 'reject' recycled water may not always be a meaningful choice in practical terms, particularly where 'rejection' implies not using water from the tap, and that such stated intentions may not be borne out in reality.

Despite these limitations, studies of behavioural intentions towards hypothetical reuse scenarios (in this and other strands) are one of the most pragmatic ways of gaining insight into public attitudes and concerns. A valuable alternative approach is to study actual reactions to real-world reuse schemes (e.g. Goodwin et al. 2017). However, such studies are necessarily retrospective and limited to contexts where actual reuse schemes are planned or in place. Therefore both approaches are needed as they can complement and challenge one another.

\section{Trust, risk perceptions, and affective reactions}

As previously mentioned, one of the key insights arising from the modelling studies discussed above is the view that knowledge of water reuse, and associated understanding of its potential environmental benefits, on its own is not necessarily a significant driver of public responses. This finding has helped cast doubt over the 'deficit model' of public responses in the context of reuse i.e. the notion that simply improving public knowledge of the technology is the key to securing acceptance (Stenekes et al. 2006). It has also helped draw attention to other, more deep-rooted factors shaping public reactions, such as trust in water service organisations, and/or in the government agencies that oversee water services, risk perceptions, and emotional (affective) reactions.

Perceptions of risk (and particularly health risk) associated with the use of recycled water have long been seen as a significant factor in shaping responses to reuse practices (Baggett et al. 2006, Hartley 2006). Recent work has argued that adoption/rejection of reuse schemes can be simulated through the application of a 'risk publics' framework, a theoretical model of how different groups perceive risks related to new technologies (Kandiah et al. 2014, 2017). However, researchers are increasingly recognising the importance of the relationship between risk perceptions and trust in the institutions or organisations that oversee reuse schemes (e.g. Leviston et al. 2013, Goodwin et al. 2017). As previously mentioned, several modelling-based studies have argued 
that higher levels of trust are associated with lower perceptions of risk, which in turn increase the likelihood of acceptance (Nancarrow et al. 2009, Bratanova et al. 2013, Ross et al. 2014). In addition, a large number of studies from different approaches have found that trust is actually one of the most important factors in determining the acceptance of water reuse (Ormerod \& Scott 2013, Aitken et al. 2014, Ross et al. 2014, Mankad \& Walton 2015).

A study examining the acceptance of genetically modified food (Eiser et al. 2002) has articulated two possible views for this link between trust and risk perceptions. The 'causal-chain' view holds that trust in the overseeing organisations ultimately determines how people process and interpret riskrelated information about the technology in question, which then shapes their decision about whether to accept the given technology. However, the same study also proposed an alternative 'associationist' view, which holds that both trust and risk perceptions are independently influenced by underlying attitudes. Importantly, this associationist interpretation suggests that the likelihood of acceptance of a particular technology is to some degree pre-determined through underlying attitudes. This, in turn, affects how people interpret both the motivations and capabilities of overseeing organisations (trust) as well as riskrelated information (risk perceptions).

While acknowledging that both models are likely to be operating simultaneously in the context of 'controversial' issues, in their review of evidence, Eiser et al. (2002) found greater support for the associationist model rather than the causal model. This resonates with more recent work that has specifically tested the causal view, which has found that trust is more a consequence of attitudes towards acceptance, rather than a driver of them (Frewer et al. 2003, Poortinga \& Pidgeon 2005). While this distinction has never specifically been tested in the context of water reuse, it's potential importance has been flagged (Fife-Shaw et al. 2008). Specifically, this view could challenge (to a degree) the emerging view of trust as the most significant factor underpinning acceptance of reuse. It implies that public engagement activities designed to improve trust in the organisations overseeing water reuse schemes may not, on their own, improve the acceptability of schemes to a significant degree.

The underlying attitudes in the 'associationist' view are linked with affective (emotional) reactions. In the context of reuse, such reactions are often referred to as the 'yuck factor' - a term used to describe the visceral reaction of dread or disgust associated with recycled wastewater. The 'yuck factor' is a longrecognised influence on public reactions to reuse schemes and other technologies (e.g. Dishman et al. 1989, Schmidt 2008). The socio-psychological modelling studies discussed above often found this emotional reaction to be a strong predictive factor in behavioural intentions towards reuse (Po et al. 2005, Nancarrow et al. 2009). It has become associated with the 'affect heuristic', which holds that people's willingness to accept a given hazard is determined by an emotional response (affect) which precedes the cognitive evaluation of information (Finucane et al. 2000, Fife-Shaw et al. 2008). In a similar vein, studies have argued that the 'experiential system' (based on affective reactions, associations, images) is much more important than the 'analytical system' 
(based on logic, reasoning, evidence) in shaping acceptance of new technology (e.g. gene technology) in the minds of the lay public (Connor \& Siegrist 2010). As a result, some have called for more in-depth explorations of how these emotional reactions shape responses to 'alternative' water systems, including reuse (Mankad 2012).

In the context of reuse, this affective response has been linked to the concept of 'magical contamination' or 'contagion', stemming from the feeling of 'once in contact, always in contact' (Rozin et al. 1986, Callaghan et al. 2012, Rozin et al. 2015). The effect of this affective reaction is that it renders people unable to divorce the final product of water reuse (clean water) from its contaminated source (human excreta) despite the fact that, scientifically, no trace of the original contamination exists. Similarly, Wester et al. (2015) identified pathogen disgust as the central facet of the emotional discomfort associated with reuse. Following the associationist model discussed above, this may pre-determine, to some extent, an individual's acceptance of recycled water, which in turn affects how they process and interpret information related to the scheme and the overseeing organisations. Furthermore, because it is a pre-cognitive 'gut reaction', it cannot be overcome solely through rational means such as improving public knowledge of water reuse in general.

Another recent study argued that these affective reactions around 'contagion' underpin a 'social representation' of water reuse - a way in which it is understood in the public domain - that differs significantly from a scientific understanding (Callaghan et al. 2012). The authors point out that individuals may be aware of, and influenced by, the social representation of water reuse, even if they themselves do not fully adopt that representation. This illustrates that, while there is (justifiably) considerable interest in understanding how responses to reuse are shaped by these deeply rooted internal factors (i.e. related to individuals' cognitive and emotional processes), there is also significant interest in the external dimension - understanding the linkages with wider societal contexts, trends and processes. This societal focus is also fostered by those who have argued that there is an over-emphasis on the 'yuck' discourse, which can undermine efforts to develop more well rounded approaches to public engagement around water reuse, and that there is a need to shift towards more socio-technical understandings of responses (e.g. Russell \& Lux, 2009). These social aspects are the focus of the final strand of research in this field.

\section{Social influences and socio-technical perspectives}

The potential influence of social context was acknowledged to a limited degree in the socio-psychological modelling studies discussed above, through the inclusion of a 'subjective norms' variable - characterised as "the influence a person feels from other people" (Nancarrow et al. 2009: 3206). These personal influences can potentially counterbalance negative affective responses, but they can also potentially reinforce and amplify those negative responses (Po et al. 2005, Dolnicar et al. 2011). 
A related area of research involves assessing and understanding the impacts of different kinds of messages, which can vary in terms of content, style, complexity, medium, etc., on public attitudes towards reuse. Only a limited number of studies have tackled this to date (Dolnicar et al. 2010, Fielding \& Roiko 2014, Price at al. 2015). In general, they have found that the provision of information regarding water reuse can have a measurable, positive influence on respondents' attitudes towards the concept, although the effects tend to be small. This is perhaps consistent with the findings discussed in the previous sections, that knowledge tends not to be a decisive driver of intended behaviour / acceptance.

The work of Price et al. (2015), in particular, highlights that pre-existing audience characteristics can significantly affect responses to a given message. For instance, those who are, or may be, directly affected by an actual reuse scheme are more likely to process, and respond positively to, risk-related information, compared to those for whom reuse is a hypothetical scenario. Additionally, those with neutral or ambivalent pre-existing attitudes are more likely to respond positively to simple, one-sided messages (i.e. messages that focus solely on the advantages of reuse) compared to those with strongly positive or negative pre-existing attitudes. Similarly, Kemp et al. (2012) found that communication campaigns based on inoculation theory - i.e. with the intention of 'inoculating' respondents against scare campaigns related to reuse were largely ineffective, as respondents were resistant to messaging.

It is worth noting that the studies discussed above are centred mainly around the one-off provision of text-based information. The effects of long-term public engagement strategies that provide messages through multiple media are much more difficult to gauge. One study did examine reactions to a video message that characterised water reuse as a 'natural' or 'normal' part of the water cycle. Though the study was limited, findings indicated that the video's overall message that 'all water is recycled' seemed to boost respondents' support towards reuse (WRF 2012), which is in keeping with previously mentioned findings that awareness of de facto reuse is positively linked with acceptability (Rice et al. 2016). Additionally, similar results were achieved through a video message on de facto reuse shown in focus group meetings with citizens (Frijns et al. 2016). These results highlight that there is considerable scope for further analysis here.

As previously mentioned, work on public reactions to GM foods has found that experience and affect are more important than cognitive analysis in shaping people's reactions to controversial technology. For this reason, researchers have argued that "[n]arratives and metaphors will be more important for the acceptance of gene technology than basic scientific knowledge or results of risk assessments" (Connor \& Siegrist 2010: 534). Given the findings above, such an argument could equally be applied to water reuse, and some authors have started to highlight the effects of narrative, discourse and social norms in public reactions to reuse (Ching \& Yu 2010, Ching 2015). As a result, public engagement around reuse is perhaps best viewed as an overall process of building and shaping a positive narrative. Such a process would necessarily include basic information provision and knowledge transfer activities, but these activities on 
their own are unlikely to shift public reactions significantly. Narrative building implies a much more holistic approach with a broad range of communication styles and mechanisms, which can appeal to affective reactions as well as cognitive ones. Indeed, studies have previously argued that engagement around reuse (particularly for potable applications) should include more experiential activities, such as tasting opportunities or filling public swimming pools (Dolnicar et al. 2011, Frijns et al. 2016).

Such findings mark the intersection between psychological and societal understandings of responses to reuse. As previously mentioned, some authors have argued for a shift towards socio-technical perspectives that situate reactions to water reuse within a broader understanding of societal systems (Russell \& Lux 2009). In this vein, a more recent and particularly fruitful line of research has examined public responses to reuse as part of a much broader societal process of technological legitimation (Harris-Lovett et al. 2015, Binz et al. 2016). The findings of this work, which has focused on the implementation of reuse schemes in California (including the San Diego example discussed earlier), show that 'acceptance' of reuse technology must be understood as a "complex socio-technical development process" and that recent successes in California are the result of a "40-year-long system-building process" to legitimize potable reuse (Binz et al. 2016: 259). While this is not the first time reuse has been characterised as part of a wider socio-technical system (e.g. Ormerod \& Scott 2013), this recent work is the first to categorise the different processes at work (what the researchers term 'institutional work') between a wide range of actors, occurring at different stages of technological development (from initial innovation to general validation). By illustrating what forms of institutional work took place (see Table 1 for selected examples), and importantly, who drove them, the researchers are able to articulate a very comprehensive and nuanced history of reuse development in California. They particularly highlight the importance of intermediaries, which are organisations that can provide support from a position of apparent independence from the chief proponents of a given technology. In the Californian case these intermediaries were an industry association and a research foundation which played a key role in constructing new normative networks by facilitating 'independent expert panels' (Binz et al. 2016).

As with all such retrospective analyses, questions remain as to whether a 'successful' legitimation process can be fostered from an early stage, or recognised only in hindsight. Nonetheless, the analysis offers some powerful insight into the range of engagement activities that can support legitimation. Equally, it also illustrates the kinds of strategies that opponents of reuse schemes have successfully employed to undermine legitimation. For instance, the chief opposition group in the Toowoomba case was able to undertake a highly emotive and aggressive campaign, which was even reflected in the name of their group ('Citizens Against Drinking Sewage'). They emphasised potential health risks as well as concerns over the town's image of a 'Garden City' being replaced by 'Poowoomba', making it less attractive to investment. In this way they effectively employed negative imagery in order to appeal directly to residents' affective reactions. The effectiveness of their campaign was illustrated by the fact that 
residents' apparent opposition to reuse was ephemeral - post-referendum follow up studies showed higher levels of support for reuse (Hurlimann \& Dolnicar 2010).

Table 1 - Selected examples of forms of institutional work, related to public engagement around water reuse (adapted from Binz et al. 2016)

\begin{tabular}{ll}
\hline $\begin{array}{l}\text { Form of institutional } \\
\text { work }\end{array}$ & Examples related to water reuse \\
\hline $\begin{array}{l}\text { Changing normative } \\
\text { associations }\end{array}$ & $\begin{array}{l}\text { Associating water reuse with its positive } \\
\text { applications (e.g. groundwater augmentation) } \\
\text { instead of its source (waste/sewage disposal) }\end{array}$ \\
\hline $\begin{array}{l}\text { Constructing } \\
\text { normative networks }\end{array}$ & $\begin{array}{l}\text { Creating independent review panels for reuse } \\
\text { schemes; certification processes for treatment } \\
\text { technologies or water quality }\end{array}$ \\
\hline Mimicry & $\begin{array}{l}\text { Selling bottled recycled water alongside bottled } \\
\text { spring water }\end{array}$ \\
\hline Educating & $\begin{array}{l}\text { Providing information about treatment processes; } \\
\text { publishing results from water testing; conducting } \\
\text { tours of treatment plants }\end{array}$ \\
\hline $\begin{array}{l}\text { Valorising and } \\
\text { demonising }\end{array}$ & $\begin{array}{l}\text { Giving awards to reuse schemes, or the } \\
\text { people/organisations associated with them; using } \\
\text { celebrities to promote recycled water }\end{array}$ \\
\hline Mythologizing & $\begin{array}{l}\text { Outlining the history of a well known 'great' reuse } \\
\text { scheme }\end{array}$ \\
\hline Imagery & $\begin{array}{l}\text { Images of children drinking or playing in clean } \\
\text { water; using evocative positive terminology such } \\
\text { as 'water recycling' }\end{array}$ \\
\hline
\end{tabular}

\section{Discussion}

The field of research around public attitudes and responses towards water reuse has evolved considerably in the past decade. As previously mentioned, the four strands of inquiry discussed above are not intended to be mutually exclusive, as many of the studies discussed sit across multiple strands. However, they do highlight some subtle shifts in emphasis and thinking that have occurred within the field. The first two strands illustrate how our understanding of the breadth of factors that influence responses to reuse, and the complex interrelationships between those factors, has become more sophisticated. The socio-psychological modelling studies in particular laid some of the groundwork for the latter two strands. The third strand encompasses a body of work that has delved much deeper into understanding how internal cognitive and emotional processes ultimately affect willingness to accept (use) recycled water, fed by engagement with risk perception and psychology literatures. At the same time, the fourth strand illustrates more of an external focus on how responses to reuse are shaped by wider social processes and narratives, supported by engagement with literature around social constructivism and socio-technical systems theory. Both 
avenues are generating fruitful insights and there is considerable potential for cross-fertilisation between them.

In revisiting Hartley's (2006) ten key factors underpinning public reactions, it becomes clear how our overall understanding of the field is shifting. Several of them have lost some relevance. For instance, Hartley asserted that acceptance is more likely when the 'degree of human contact is minimal'. However, recent developments in potable reuse schemes (indirect and direct) and the support that these have generated (e.g. in San Diego) have shown that this is no longer (necessarily) such a significant factor. Similarly, 'awareness of water supply problems' and the 'promotion of water conservation' as an outcome do not necessarily improve acceptance of reuse - indeed, treating water reuse as a mechanism to address a water supply deficit can even backfire, as was demonstrated in the Western Corridor example. Hartley also argued that support for reuse would improve if 'protection of the environment' was a clear benefit, whereas subsequent research has not found it to be a significant factor.

Other factors identified by Hartley remain important considerations, such as 'perception of water quality' and 'confidence in local management'. The literature on risk perception and trust in overseeing organisations discussed above highlights the development of a much more sophisticated understanding of these factors. Additionally, there are several important aspects of current thinking which did not feature in Hartley's initial list. For instance, the list had no apparent mention of 'yuck factor' reactions (though these had been recognised in work that pre-dated Hartley's paper). However, some of the most significant advancements in thinking in this field stem from the increasingly sophisticated understanding of the 'yuck factor' and the role of such pre-cognitive affective reactions in shaping responses. Similarly, recent research has shown that awareness of existing unplanned (de facto) reuse practices has the potential to improve acceptance, something which was not considered in Hartley's list. This emerging point even challenges one of the factors Hartley identified, namely that acceptance is more likely if 'perception of wastewater as the source of reclaimed water is minimal'.

The socio-psychological modelling approaches, based on the theory of planned behaviour, added depth and nuance to some of Hartley's initial factors, but one of the key challenges to these approaches is that their findings are based on stated intentions, which are not necessarily reflective of actual behaviour towards water reuse. The next strand of thinking emphasised the importance of trust in the quality of recycled water and in the organisations involved in its management. However, one of the key challenges here is that trust, and efforts to build trust through public engagement, may ultimately be shaped by precognitive reactions, i.e. the 'yuck factor'. These emotional, intuitive processes are deeply entrenched within individuals, and some have argued that an overemphasis on the 'yuck factor' in this field can foster the unhelpful view that public reactions to reuse are virtually unchangeable. However, other research has illustrated that these emotional reactions at the individual level are also linked with wider societal processes and social representations (though these links are not yet well understood). The final strand of thinking builds on this 
social understanding, and findings suggest that public engagement around reuse could best be viewed as situated within an overall process of technological 'legitimation' (as presented in the work of Binz et. al). The ultimate long-term outcome of that legitimation process, particularly for potable applications, is arguably that recycled water becomes 'normalised', so that it is considered equal to other water sources. In other words, water reuse would effectively become a conventional water source, 'part of the mix' in providing secure water resources. This process could be supported by the development of long-term narratives around the benefits of adopting reuse, which could potentially build on heightened awareness of de facto reuse and the recognition that 'all water is recycled'. Narratives can appeal to affective reactions and experiential processes, as well as cognitive ones. The 'forms of institutional work' discussed in the legitimation studies highlight the range of potential mechanisms that can be employed. This may help stimulate some novel thinking around approaches to engagement.

\section{Conclusion}

This review has showcased current evidence and thinking around public responses to water reuse, and highlighted the novel insights and shifts in emphasis that have occurred since Hartley's (2006) work was published.

For practitioners involved with the planning and delivery of water reuse schemes, and other controversial environmental technologies, the key insight to be gained from these four interrelated strands of thinking is that 'standard' public engagement activities, such as the simple provision of information related to schemes, may not (on their own) achieve any meaningful shifts in public attitudes. That is not to say, however, that such awareness raising and information provision activities are unimportant or irrelevant. Rather, we argue that there is perhaps a need for more comprehensive thinking around public engagement approaches. A wide range of activities, appealing to both rational and emotional/experiential processes, and undertaken/supported by a wide range of actors, is ultimately what underpins a broader social shift towards legitimising water reuse.

For academia, the findings and insights that have accumulated in the past decade suggest some very interesting potential directions for future work around understanding public responses towards water reuse. Again, these avenues of inquiry are not limited to water reuse, but are relevant across a wide range of environmental technologies. Work is still needed to understand if/how legitimation processes, supported by narrative building and other forms of institutional work, can be fostered in different contexts. The 'social representation' of recycled water will inevitably be shaped by a wide range of contextual factors and social actors. There is also clear scope for research to develop a better understanding of how the 'yuck factor' pre-cognitive affective reactions influence responses to reuse, and how these might be affected by different forms of social narrative. In other words, there is a need for more crossdisciplinary efforts that bring deep psychological insights at the level of the 
individual together with insights from a societal level that situate water reuse within socio-technical and social constructivist perspectives. Such efforts will allow the field to move past the view that deeply entrenched emotional reactions are fixed, and improve understandings of how they can potentially be shifted through long-term societal legitimation and narrative building processes.

Additionally, as more and more reuse schemes are implemented, future research will continue to benefit from efforts to marry work based on hypothetical reuse scenarios (including behavioural intentions studies) with empirical insights from real-world schemes. Importantly, studies based on real-world schemes should focus on those that have generated positive and/or ambivalent reactions, not just those that have faced opposition. Finally, it is clear that much of the work in this area has benefited from strong engagement with other related literatures (risk perception, behavioural psychology, socio-technical theory, etc.) and future research should continue to promote cross-fertilisation, particularly around the challenging aspect of understanding affective reactions.

\section{Acknowledgements}

This research was conducted as part of the "Innovation Demonstration for a Competitive and Innovative European Water Reuse Sector" (DEMOWARE) project. DEMOWARE has received funding from the European Union's 7th Framework Programme under grant agreement no 619040. 


\section{References}

Aitken, V., Bell, S., Hills, S., \& Rees, L. (2014) Public acceptability of indirect potable water reuse in the south-east of England. Water Science \& Technology: Water Supply, 14(5), pp. 875-885.

Ajzen, I. (1985) From intentions to actions: A theory of planned behaviour. Pp. 11-39 in J. Kuhl and J. Beckmann (eds.), Action-control: From cognition to behavior, Springer, Heidelberg.

Baggett, S., Jeffrey, P. \& Jefferson, B. (2006) Risk perception in participatory planning for water reuse. Desalination, 187(1-3), pp. 149-158.

Binz, C., Harris-Lovett , S., Kiparsky, M., Sedlak, D.L., \& Truffer, B. (2016) The thorny road to technology legitimation - Institutional work for potable water reuse in California. Technological Forecasting and Social Change, 103, pp. 249263.

Bratanova, B., Morrison, G., Fife-Schaw, C., Chenoweth, J. \& Mangold, M. (2013) Restoring drinking water acceptance following a waterborne disease outbreak: the role of trust, risk perception, and communication. Journal of Applied Social Psychology, 43(9), pp. 1761-1770.

Bridgeman, J. (2004) Public perception towards water recycling in California. Water and Environment Journal, 18(3), pp. 150-154.

Brouwer, S., Maas, T., Smith. H.M. \& Frijns, J. (2015) Trust in Water Reuse: Review Report on International Experiences in Public Involvement and Stakeholder Collaboration, DEMOWARE project deliverable D5.2.

Bruvold, W.H. (1985) Obtaining public support for reuse water. Journal of the American Water Works Association, 77(7), pp. 72-77.

Callaghan, P., Moloney, G., and Blair, D. (2012) Contagion in the Representational Field of Water Recycling: Informing New Environment Practice Through Social Representation Theory. Journal of Community \& Applied Social Psychology, 22(1), pp. 20-37.

Ching, L. (2015) A quantitative investigation of narratives: recycled drinking water. Water Policy, 17(5), pp. 831-847.

Ching, L. and Yu, D.J.H. (2010) Turning the tide: informal institutional change in water reuse. Water Policy, 12(S1), pp. 121-134.

City of San Diego. (2013). Water Purification Demonstration Project. Retrieved $11^{\text {th }}$ August 2016 from:

http://www.sandiego.gov/water/pdf/purewater/prdemo.pdf 
City of San Diego. (2015). Pure Water San Diego. Retrieved 11 $11^{\text {th }}$ August 2016 from: http://www.sandiego.gov/water/pdf/purewater/2015/fs_purewater.pdf

Connor, M. \& Siegrist, M. (2010) Factors Influencing People's Acceptance of Gene Technology: The Role of Knowledge, Health Expectations, Naturalness, and Social Trust. Science Communication, 32(4), pp. 514-538.

Dishman, C.M., Sherrard, J.H. \& Rebhun, M. (1989) Gaining support for direct potable water reuse. Journal of Professional Issues in Engineering, 115(2), pp. 154-161.

Dolnicar, S., Hurlimann, A. and Nghiem, L.D. (2010) The effect of information on public acceptance-The case of water from alternative sources. Journal of Environmental Management, 91(6), pp. 1288-1293.

Dolnicar, S., Hurlimann, A. and Grun, B. (2011) What affects public acceptance of recycled and desalinated water? Water Research, 45(2), pp. 933-943.

Eiser, J.R., Miles, S. \& Frewer, L.J. (2002) Trust, perceived risk and attitudes towards food technologies. Journal of Applied Social Psychology, 32, pp. 24232433.

Fielding, K.S., and Roiko, A.H. (2014) Providing information promotes greater public support for potable recycled water. Water Research, 61, pp. 86-96.

Fielding, K.S., Gardner, J., Leviston, Z. and Price, J. (2015) Comparing Public Perceptions of Alternative Water Sources for Potable Use: The Case of Rainwater, Stormwater, Desalinated Water, and Recycled Water. Water Resources Management, 29(12), pp. 4501-4518.

Fife-Schaw, C., Barnett, J., Chenoweth, J., Morrison, G.M., \& Lunde, C. (2008) Consumer trust and confidence: some recent ideas in the literature. Water Science \& Technology: Water Supply-WSTWS, 8(1), pp. 43-48.

Finucane, M.L., Alhhakami, A.S., Slovic, P. \& Johnson, S.M. (2000) The affect heuristic in the judgement of risks and benefits. Journal of Behavioural Decision Making, 13, pp. 1-17.

Frewer, L.J., Miles, S. \& Marsh, R. (2002) The Media and Genetically Modified Foods: Evidence in Support of Social Amplification of Risk. Risk Analysis, 22(4), pp. 701-711.

Frewer, L.J., Scholderer, J. \& Bredahl, L. (2003) Communicating about the Risks and Benefits of Genetically Modified Foods: The Mediating Role of Trust. Risk Analysis, 23(6), pp. 1117-1133.

Friedler, E. (2008). The water saving potential and the socio-economic feasibility of greywater reuse within the urban sector-Israel as a case study. International Journal of Environmental Studies, 65(1), pp. 57-69. 
Friedler, E. \& Lahav, O. (2006) Centralised urban wastewater reuse: what is the public attitude? Water Science \& Technology, 54(6), pp. 423-430.

Frijns J., Smith, H.M., Brouwer, S., Garnett, K., Elelman, R. \& Jeffrey, P. (2016) How governance regimes shape the implementation of water reuse schemes. Water 8(12), pp. 605.

Garcia-Cuerva, L., Berglund, E.Z. \& Binder, A.R. (2016) Public perceptions of water shortages, conservation behaviors, and support for water reuse in the U.S.. Resources, Conservation and Recycling, 113, pp. 106-115.

Goodwin, D., Raffin, M., Jeffrey, P. and Smith H.M. (2017, in press) Evaluating media framing and public reactions in the context of a water reuse proposal. International Journal of Water Resources Development, online (http://dx.doi.org/10.1080/07900627.2017.1347085).

Harris-Lovett, S.R., Binz, C., Sedlak, D.L., Kiparsky, M., \& Truffer, B. (2015) Beyond User Acceptance: A Legitimacy Framework for Potable Water Reuse in California. Environmental Science \& Technology, 49(13), pp. 7552-7561.

Hartley, T.W. (2006) Public perception and participation in water reuse. Desalination, 187, pp. 115-126.

Hills, S., Birks, R. \& McKenzie, B. (2002) The Millennium Dome "Watercycle" experiment: to evaluate water efficiency and customer perception at a recycling scheme for 6 million visitors. Water Science \& Technology, 46(6), pp. 233-240.

Hills, S., Lambert, C., Aitken, T., and Bell, S.J. (2013) Investigating attitudes to "planned" Indirect Potable Reuse in London using quantitative on-line surveys. In: (Proceedings) 9th IWA International Conference on Reuse, Windhoek.

Hurlimann, A., Hemphill, E., McKay, J., \& Geursen, G. (2008) Establishing components of community satisfaction with recycled water use through a structural equation model. Journal of Environmental Management, 88(4), pp. 1221-1232.

Hurlimann, A., Dolnicar, S., \& Meyer P. (2009) Understanding behaviour to inform water supply management in developed nations - a review of literature, conceptual model and research agenda. Journal of Environmental Management, 91(1), pp. 47-56.

Hurlimann, A. \& Dolnicar, S. (2010) When public opposition defeats alternative water projects: the case of Toowoomba Australia. Water Research, 44(1), pp. 287-297.

Hurlimann, A. \& Dolnicar, S. (2016) Public acceptance and perceptions of alternative water sources: a comparative study in nine locations. International Journal of Water Resources Development, 32(4), pp. 650-673. 
Jansen, H.P., Stenstrom, M.K. \& deKoning, J. (2007) Development of indirect potable reuse in impacted areas of the United States. Water Science and Technology, 55(1), pp. 357-66.

Johnstone, C. (2009) Water recycling pipeline in mothballs. The Courier Mail, $8^{\text {th }}$ May 2009, retrieved 11 th August 2016 from:

http://www.couriermail.com.au/news/queensland/recycle-pipeline-inmothballs/story-e6freoof-1225710435782

Kandiah, V., Berglund, E., \& Binder, A. (2014) Empirical Acceptance-Resistance Agent-Based Modeling Approach for Simulating the Adoption of Water Reuse. Paper presented to the World Environmental and Water Resources Congress, June 1-5 2014, Portland, Oregon.

Kandiah, V., Binder, A., \& Berglund, E. (2017) An Empirical Agent-Based Model to Simulate the Adoption of Water Reuse Using the Social Amplification of Risk Framework. Risk Analysis, 37(10), pp. 2005-2022.

Kemp, B., Randle, M., Hurlimann, A. and Dolnicar, S. (2012) Community acceptance of recycled water: can we inoculate the public against scare campaigns? Journal of Public Affairs, 12(4), pp. 337-346.

Lazarova, V., Asano, T., Bahri, A., and Anderson, J. (eds) (2013) Milestones in Water Reuse: the Best Success Stories. IWA Publishing, London.

Leviston, Z., Browne, A.L., and Greenhill, M. (2013) Domain-based perceptions of risk: a case study of lay and technical community attitudes toward managed aquifer recharge. Journal of Applied Social Psychology, 43(6), pp. 1159-1176.

Mankad, A. \& Tapsuwan, S. (2011) Review of socio-economic drivers of community acceptance and adoption of decentralised water systems. Journal of Environmental Management, 92(3), pp. 380-391.

Mankad, A. (2012) Decentralised water systems: Emotional influences on resource decision making. Environment International, 44, pp. 128-140.

Mankad, A. \& Walton, A. (2015) Accepting managed aquifer recharge of urban storm water reuse: The role of policy-related factors. Water Resources Research, 51(12), pp. 9696-9707.

Marks, J.S. (2006) Taking the public seriously: The case of potable and nonpotable reuse. Desalination, 187, pp. 137-147.

Marks, J.S., Martin, B. \& Zadoroznj, M. (2006) Acceptance of water recycling in Australia: National baseline data. Water, 33(2), pp. 151-157. 
Mather, D.W., Knight, J.G., Insch, A., Holdsworth, D.K., Ermen, D.F. \& Breitbarth, T. (2012) Social Stigma and Consumer Benefits: Trade-Offs in Adoption of Genetically Modified Foods. Science Communication, 34(4), pp. 487-519.

Meehan, K., Ormerod, K.J. \& Moore, S.A. (2013) Remaking waste as water: The governance of recycled effluent for potable water supply. Water Alternatives, 6(1), pp. 67-85.

Michell, N. (2016) The role of water in the circular economy. The Source, May $1^{\text {st }}$ 2016, retrieved May 24th 2016 from: http://www.thesourcemagazine.org/therole-of-water-in-the-circular-economy

Nancarrow, B.E., Leviston, Z., Po, M., Porter, N.B. and Tucker, D.I. (2008) What drives communities' decisions and behaviours in the reuse of wastewater? Water Science and Technology, 57(4), pp. 485-491.

Nancarrow, B.E., Leviston, Z., and Tucker, D.I. (2009) Measuring the predictors of communities' behavioural decisions for potable reuse of wastewater. Water Science and Technology, 60(2), pp. 3199-3209.

Ormerod, K.J. \& Scott, C.A. (2013) Drinking wastewater: Public trust in potable reuse. Science, Technology \& Human Values, 38(3), pp. 351-373.

Po, M., B.E. Nancarrow \& J.D. Kaercher (2003) Literature review of factors influencing public perceptions of water reuse. CSIRO Land and Water, Melbourne.

Po, M., Nancarrow, B., Leviston, Z., Porter, N., Syme, G. \& Kaercher, J. (2005) Predicting Community Behaviour in Relation to Wastewater Reuse: What Drives Decisions to Accept or Reject? CSIRO Land and Water, Melbourne.

Poortinga, W. \& Pidgeon, N.F. (2005) Trust in Risk Regulation: Cause or Consequence of the Acceptability of GM Food? Risk Analysis, 25(1), pp. 199-209.

Porter, N.B., Leviston, Z., Nancarrow, B.E., Po, M. \& Syme, G.J. (2005) Interpreting householder preferences to evaluate water supply systems: An attitudinal model. CSIRO Land and Water, Perth.

Price, J., Fielding, K. \& Leviston, Z. (2012) Supporters and opponents of potable recycled water: culture and cognition in the Toowoomba referendum, Society \& Natural Resources, 25(10), pp. 980-995.

Price, J., Fielding, K.S., Gardner, J., Leviston, Z. \& Green, M. (2015) Developing effective messages about potable recycled water: The importance of message structure and content. Water Resources Research, 51, pp. 2174-2187.

Robinson, K. G., C.H. Robinson \& S.A. Hawkins, S.A. (2005) Assessment of public perception regarding wastewater reuse. Water Supply, 5(1), pp. 59-65. 
Rice, J., Wutich, A., White, D.D., \& Westerhoff, P. (2016) Comparing actual de facto wastewater reuse and its public acceptability: A three city case study. Sustainable Cities and Society, 27, pp. 467-474.

Ross, V.L., Fielding, K.S., \& Louis, W.R. (2014) Social trust, risk perceptions and public acceptance of recycled water: Testing a social-psychological model. Journal of Environmental Management, 137, pp. 61-68.

Rowe, G. and Frewer, L.J. (2000) Public Participation Methods: A Framework for Evaluation. Science Technology Human Values, 25(1), pp. 3-29.

Rozin, P., Millman, L. \& Nemeroff, C. (1986) Operation of the laws of sympathetic magic in disgust and other domains. Journal of Personality and Social Psychology, 50(4), pp. 703.

Rozin, P., Haddad, B., Nemeroff, C. \& Slovic, P. (2015) Psychological aspects of the rejection of recycled water: Contamination, purification and disgust. Judgment and Decision Making, 10(1), pp. 50-63.

Russell, S. \& Lux, C. (2009) Getting over yuck: moving from psychological to cultural and sociotechnical analyses of responses to water recycling. Water Policy, 11(1), pp. 21-35.

Schmidt, C.W. (2008) The yuck factor: When disgust meets discovery. Environmental Health Perspectives, 116(12), pp. A524-A527.

Sleenhoff, S. \& Osseweijer, P. (2013) Consumer choice: Linking consumer intentions to actual purchase of GM labeled food products. GM Crops \& Food, 4(3), pp. 166-171.

Smith, H.M., Rutter, P. \& Jeffrey, P. (2015) Public perceptions of recycled water: A survey of visitors to the London 2012 Olympic Park. Journal of Water Reuse and Desalination, 5(2), pp. 189-195.

Stenekes, N., Colebatch, H.K., Waite, T.D. and Ashbolt, N.J. (2006) Risk and Governance in Water Recycling: Public Acceptance Revisited. Science Technology Human Values, 31(2), pp. 107-134.

Syme, G.J. \& Nancarrow, B.E. (2006) Achieving sustainability and fairness in water reform: A Western Australian case study. Water International, 31(1), pp. 23-30.

Thorley, D. (2007) Toowoomba recycled water poll. Reform, 89(Summer), pp. 49-51.

U.S. Environmental Protection Agency (EPA) (2012) Guidelines for Water Reuse. Environmental Protection Agency. Washington, DC. 
Van der Bruggen, B. (2010) The Global Water Recycling Situation. Pp. 41-62 in Escobar, I. and Schafer, A. (eds.), Sustainable Water for the Future: Water Recycling versus Desalination (Sustainability Science and Engineering, Volume 2), Elsevier, Amsterdam.

Wang, X. (2016) Water Cycle Management: A New Paradigm of Water Reuse for Cities of the Future. The Source, February 11th 2016, retrieved May 24th 2016 from: http://www.iwa-network.org/water-cycle-management-a-new-paradigmof-water-reuse-for-cities-of-the-future

Wester, J., Timpano, K.R., Çek, D., Lieberman, D., Fieldstone, S.C., \& Broad, K. (2015) Psychological and social factors associated with wastewater reuse emotional discomfort. Journal of Environmental Psychology, 42, pp. 16-23.

WRF (2012) Downstream: Research to shift community attitudes on water reuse. Water Reuse Research Foundation (WRF-09-01), Alexandria VA. 